\title{
PERFORMANCE ANALYSIS OF VOICE OPERATED WHEEL CHAIR
}

\author{
Jayesh K. Kokate 1 , A. M. Agarkar ${ }^{2}$ \\ ${ }^{1}$ Student ME, Dept. of Electronics \& Telecommunication, SSGMCE, Shegaon, Maharashtra, India \\ ${ }^{2}$ Professor, Dept of Electronics \& Telecommunication, SSGMCE, Shegaon, Maharashtra, India
}

\begin{abstract}
This paper introduces the wheel chair which is controlled by voice commands from the handicapped person. Voice commands are received by the android mobile and converted into the text and provided to the Microcontroller PIC $16 F 877$ for controlling the movement of wheel chair. The input command from the android mobile is transferred to the Microcontroller with the help of Bluetooth module wirelessly. Two DC motors are used to control the movement of wheel chair. These motors are connected to the back wheels of wheel chair with the help of a gear mechanism. Battery is used to provide the power to the DC motors. Two double pole Relays are used, which connects the battery to the DC motors and the operation of relay is controlled by the microcontroller. Two IR sections, forward and backward are used to detect the obstacle in the path of wheel chair. The block diagram, hardware used and performance analysis of wheel chair is presented in this paper.
\end{abstract}

Keywords: Voice operated Wheel Chair, Android Mobile, Bluetooth module, IR module.

\section{INTRODUCTION}

This is a voice operated wheel chair, the voice commands are provided by the handicapped person. These commands are converted into text signal with the help of an android mobile. This text signal is transferred to the Microcontroller PIC 16F877 with the help of a Bluetooth module. Microcontroller will control the movement of wheel chair according to the input command received. Two DC motors are used for the movement of wheel chair. These motors are connected to the back wheels of wheel chair with the help of a gear mechanism. Battery is used to provide the power to the DC motors. Battery is connected to the DC motors via relays and relays are used to on/off the DC motors and relays are operated by the signal from the Microcontroller.

\section{BLOCK DIAGRAM, HARDWARE \&}

\section{SOFTWARE USED}

\subsection{Block Diagram}

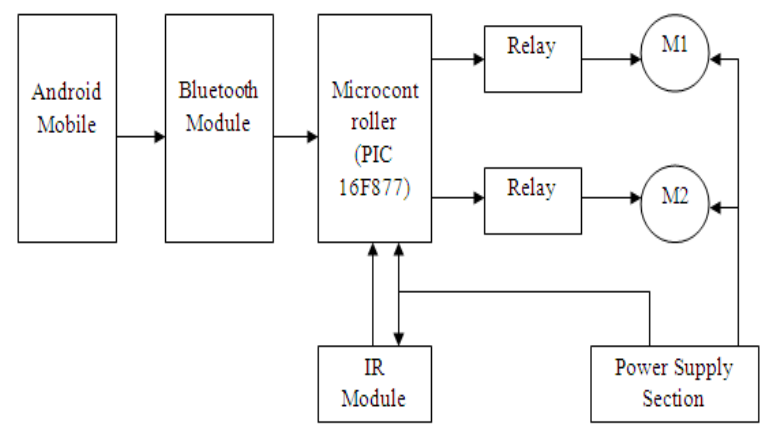

\subsection{Hardware Used}

(i) Wheel chair

(ii) Android Mobile

(iii) DC Motors

(iv) PIC 16F877 Microcontroller

(v) Bluetooth Module

(vi) IR Module

(vii) Battery

(viii) Relays

(ix) Power supply section

(x) LCD

\subsection{Software Used:}

(i) Eagle Layout.

(ii) Micro $\mathrm{C}$ for PIC.

(iii) Android App.

Fig. 1 Block Diagram 


\section{FLOWCHART}

Flow chart is as shown in Fig 1.

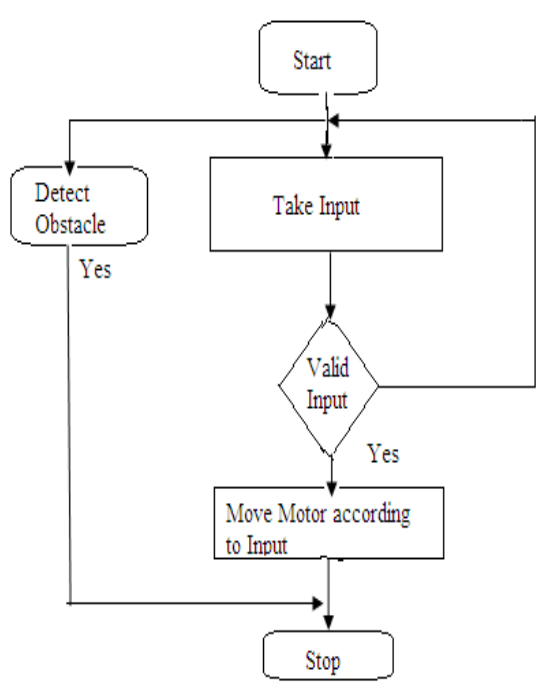

Fig. 2 Flowchart

\section{WORKING OF VOICE OPERATED WHEEL}

\section{CHAIR}

The Block diagram is as shown in fig. 1 and flow chart is as shown in fig 2. The input command from the handicapped person is received with the help of an Android mobile. This speech signal is converted into the text signal with the help of an android mobile application. This text signal is given to the Microcontroller PIC 16F77 using a Bluetooth section wirelessly, Microcontroller controls the relays connected to the DC motors. According to the input signal from handicapped person the microcontroller controls the movement of wheel chair. Battery is connected to the DC motors through relays and relays controls the DC motor ON/OFF depending upon the signal received from the microcontroller. Two IR modules are used one for forward and one for Backward to detect the obstacle in the path of wheel chair and to avoid the collision. If an obstacle is detected in the path of wheel chair then microcontroller will get the signal from the IR section and Microcontroller will stop the wheel chair. DC motors are connected in H Bridge format using Double pole relays. Commands on which Wheel chair operates are Forward, Back, Left, Right and Stop. The LCD module is also interfaced to microcontroller which indicates the working status of wheel chair. The motor operations for mention commands are given below.

Forward: Both motors are in clockwise direction.

Back: Both motors are in anticlockwise direction.

Left: Left motor clockwise and Right motor anticlockwise direction.
Right: Right motor in clockwise and Left motor in anticlockwise direction.

Stop: Both motors are stop.

\section{ADVANTAGES}

(i) Less wiring because of Bluetooth section.

(ii) Less Hardware require i.e. compact.

(iii) Economical.

(iv) Eliminate man required for transport purpose of handicapped person.

(v) User friendly.

(vi) A handicapped person even with Legs and Hand can use this and become Independent.

(vii) Very rapidly changing input can be easily recognized due to Android mobile.

(viii) Suitable for practical application as compare to HM 2007.

\section{ACTUAL PHOTOGRAPHES OF VOICE OPERATED WHEEL CHAIR}

The actual and labelled photographs are as shown in following photographs.

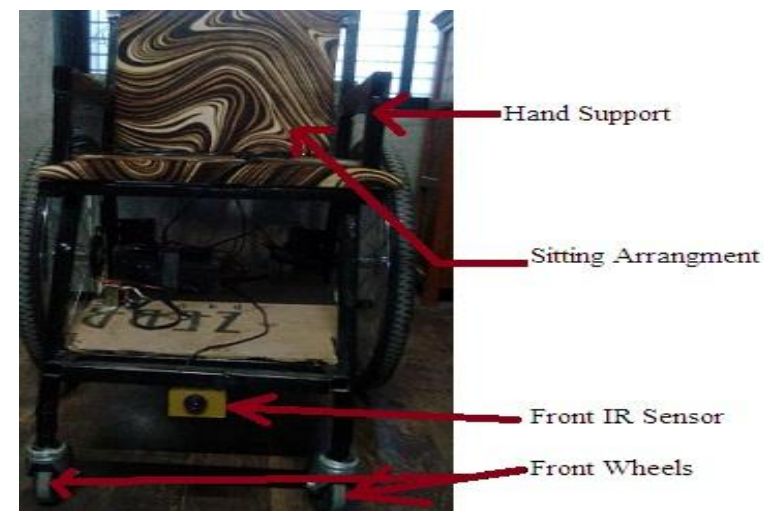

Fig 3: Front View of Wheel Chair

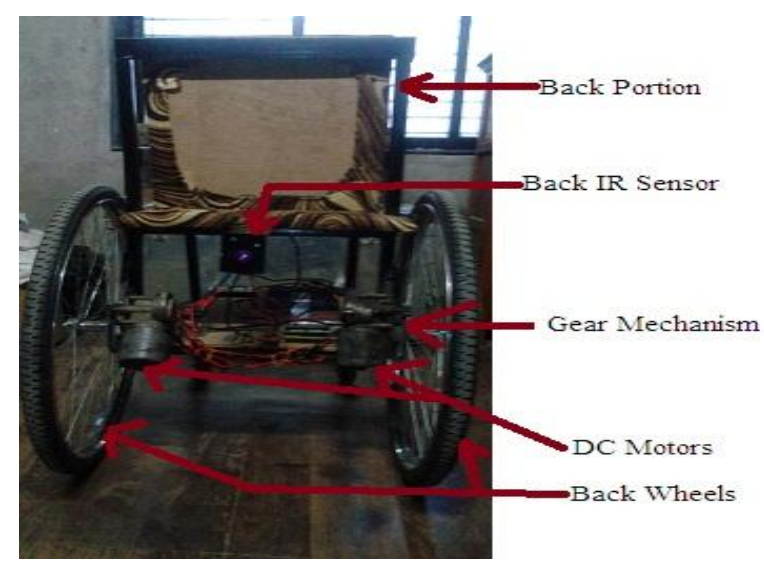

Fig 4: Back View of Wheel Chair 


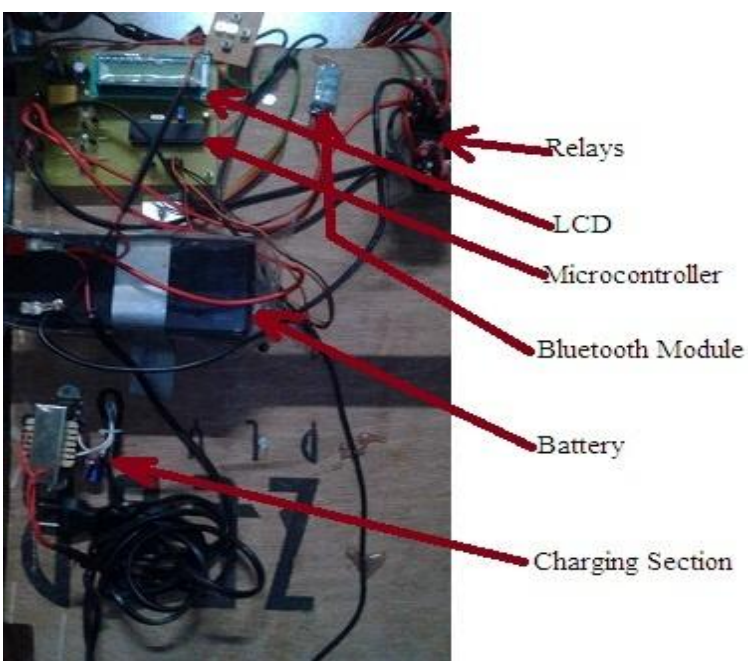

Fig 5: Electronic part

\section{RESULTS}

In this section the results are provided about the performance of wheel chair. This section is divided into two sub sections. Section 7.1 is related to the performance analysis of Obstacle detection module. 7.2 related to the Time taken by wheel chair to operate after giving the command. The testing of wheel chair was carried out on rough surface considering the conditions of rural PHC's (Primary Health Centres) and hospitals in rural, semi rural urban areas.

\subsection{Analysis of Obstacle Detection:}

Here, the analysis is carried out in a way that wheel chair is moved in forward and backward direction 5 times and measured the actual distance between the wheel chair and obstacle when the wheel chair is stopped. Also the actual distance when the IR sensor detects the obstacle is also measured. The statistics is as given for both forward and backward obstacle detection in fig 6 and 7 respectively.

\subsubsection{Forward Direction Obstacle Detection Analysis:}

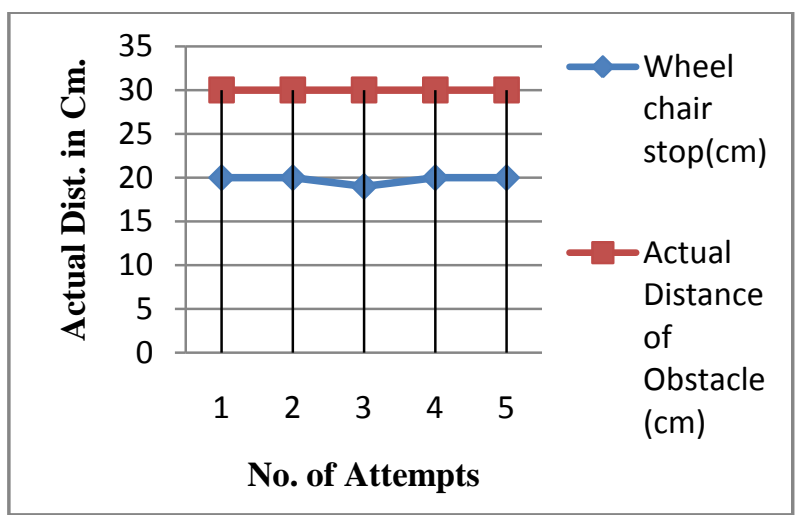

Fig 6: Forward Obstacle detection Statistics

\subsubsection{Backward Direction Obstacle Detection}

\section{Analysis}

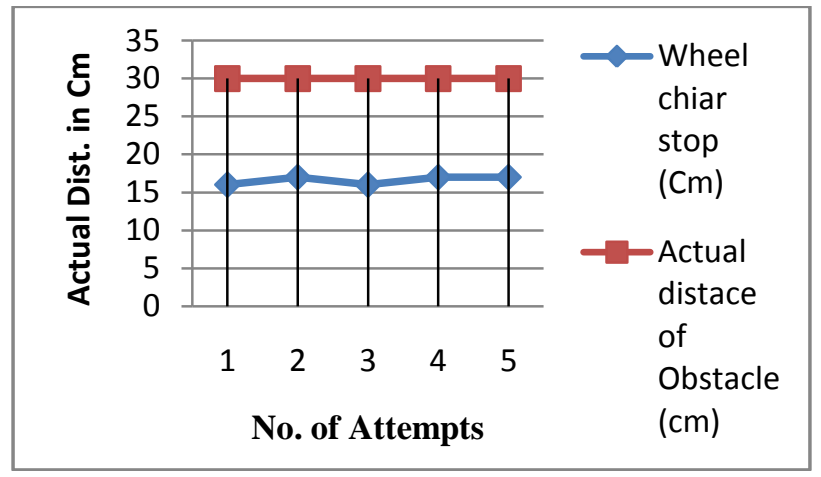

Fig 7: Backward Obstacle detection Statistics

\subsection{Analysis of Time Taken to Process Command}

Here same command is given to the wheel chair 10 times and time taken by the wheel chair to operate is considered and that statistics is given below for all commands.

\subsubsection{Forward Command}

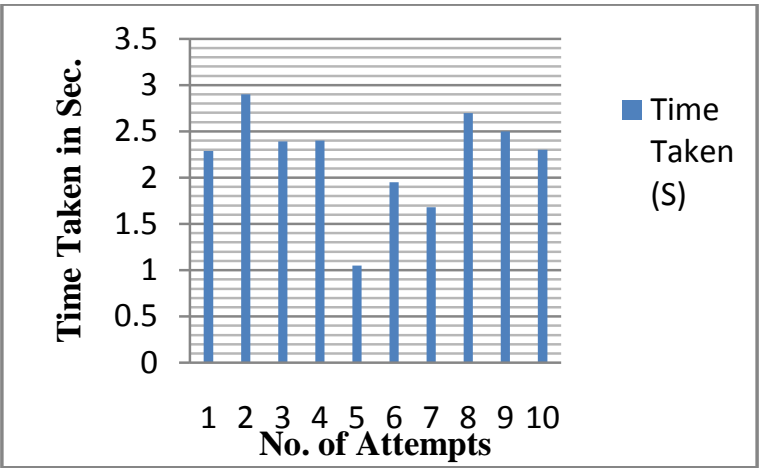

Fig 8: Forward Command statistics

\subsubsection{Back Command:}

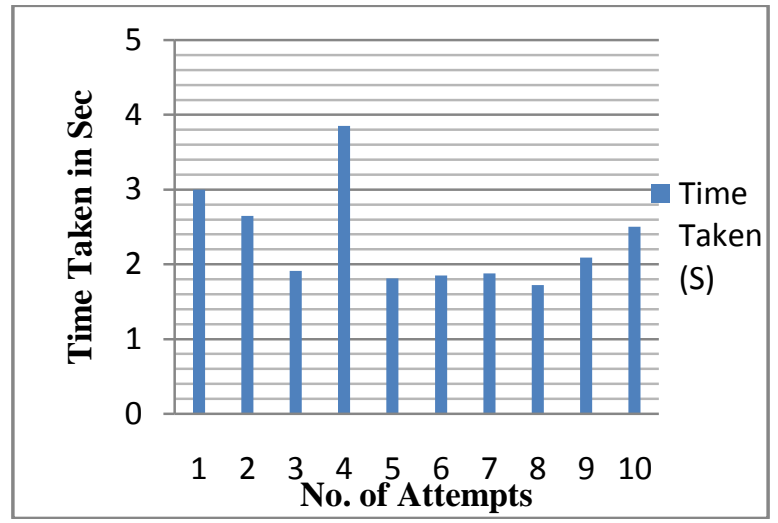

Fig 9: Back Command statistics 


\subsubsection{Left Command:}

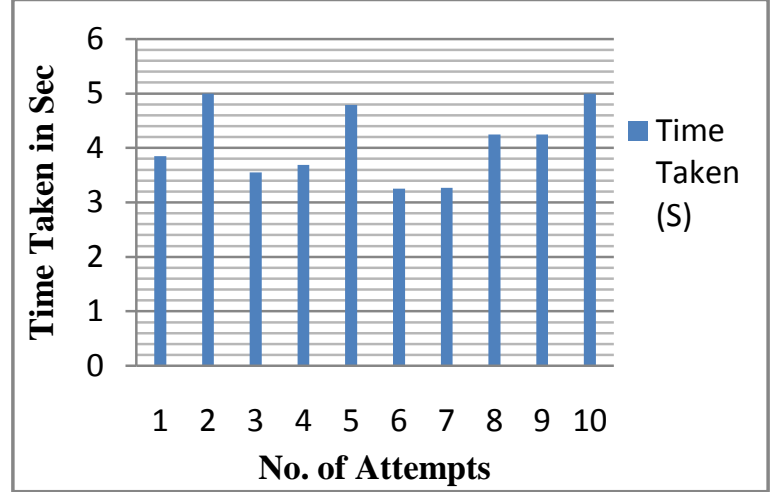

Fig 10: Left Command statistics

\subsubsection{Right Command:}

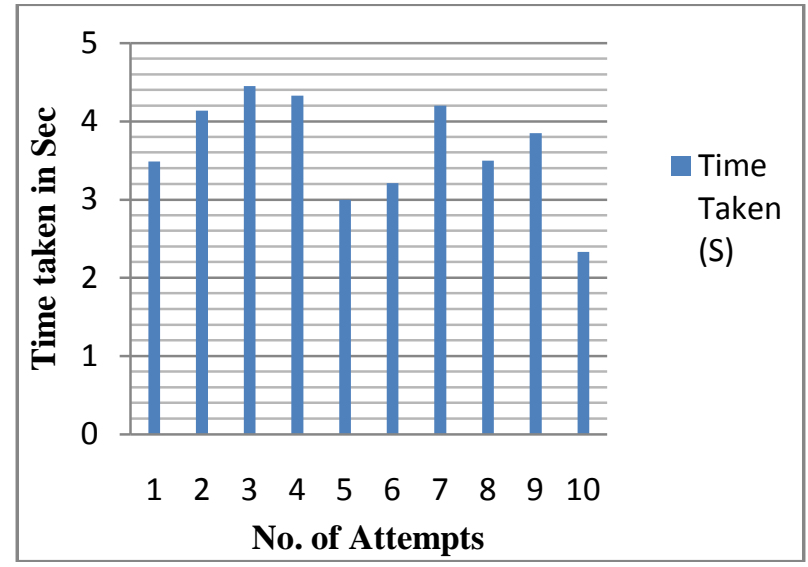

Fig 11: Right Command statistics

\subsubsection{Stop Command:}

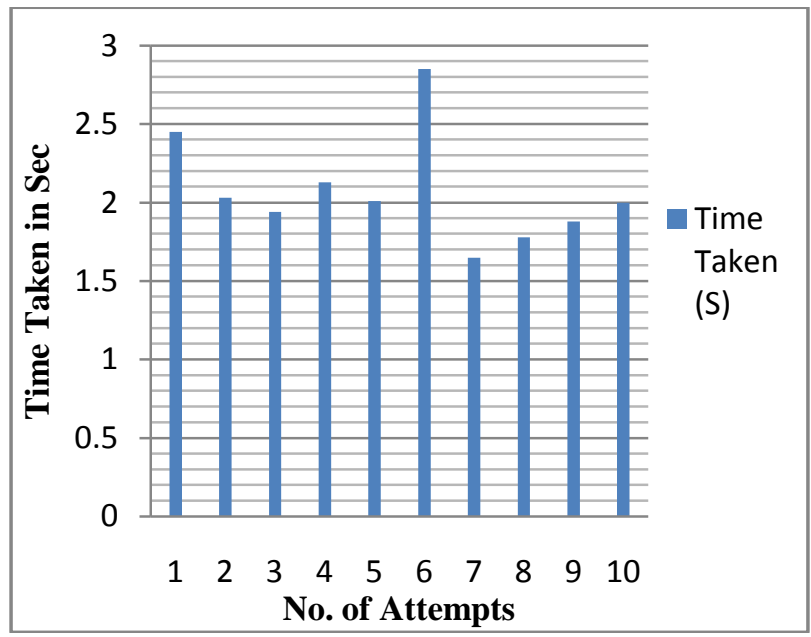

Fig 12: Stop Command statistics

\section{CALCULATIONS:}

The mean time is calculations for all input command are as given below. Mean time is calculated to know the average time taken by the wheel chair to perform the task. The formula used to calculate the mean time is as follows.

$$
\text { Mean time }=\frac{\text { Addition of time taken for } 10 \text { attempts }}{10}
$$

\section{Forward Command:}

\begin{tabular}{|c|c|c|c|c|c|c|c|c|c|c|}
\hline $\begin{array}{l}\text { Attempt } \\
\text { no }\end{array}$ & 1 & 2 & 3 & 4 & 5 & 6 & 7 & 8 & 9 & 10 \\
\hline $\begin{array}{l}\text { Time } \\
\text { taken }\end{array}$ & กิ & กิ & $\stackrel{\text { nे }}{\text { nे }}$ & 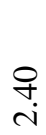 & ín & ఫே & $\stackrel{\infty}{\infty}$ & $\frac{2}{i}$ & ก & $\stackrel{\text { ñ }}{\text { ñ }}$ \\
\hline
\end{tabular}

For Forward command mean time is: $2.215 \mathrm{sec}$.

Back Command:

\begin{tabular}{|c|c|c|c|c|c|c|c|c|c|c|}
\hline $\begin{array}{l}\text { Atte } \\
\text { mpt } \\
\text { no }\end{array}$ & 1 & 2 & 3 & 4 & 5 & 6 & 7 & 8 & 9 & 10 \\
\hline $\begin{array}{l}\text { Time } \\
\text { taken }\end{array}$ & $\underset{\text { ri }}{8}$ & $\begin{array}{l}n \\
\text { d } \\
0\end{array}$ & $\bar{\sigma}$ & $\begin{array}{l}\infty \\
\infty \\
\infty\end{array}$ & 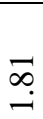 & $\stackrel{\infty}{\infty}$ & $\begin{array}{l}\infty \\
\infty \\
-\end{array}$ & $\stackrel{N}{\sim}$ & $\begin{array}{l}8 \\
\text { di }\end{array}$ & $\stackrel{\text { ก }}{\sim}$ \\
\hline
\end{tabular}

For Back command mean time is: 2.326 sec.

\section{Left Command:}

\begin{tabular}{|c|c|c|c|c|c|c|c|c|c|c|}
\hline $\begin{array}{l}\text { Atte } \\
\text { mpt } \\
\text { no }\end{array}$ & 1 & 2 & 3 & 4 & 5 & 6 & 7 & 8 & 9 & 10 \\
\hline $\begin{array}{l}\text { Time } \\
\text { taken }\end{array}$ & $\begin{array}{l}n \\
\infty \\
\dot{m}\end{array}$ & $\begin{array}{l}8 \\
\stackrel{8}{ }\end{array}$ & $\stackrel{n}{n}$ & $\begin{array}{l}\hat{\sigma} \\
\dot{r}\end{array}$ & $\stackrel{9}{\stackrel{9}{\gamma}}$ & ָூ & $\stackrel{\grave{n}}{\grave{n}}$ & 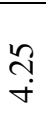 & 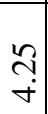 & $\begin{array}{l}8 \\
\dot{1}\end{array}$ \\
\hline
\end{tabular}

For Left command mean time is: $4.09 \mathrm{sec}$.

Right Command:

\begin{tabular}{|c|c|c|c|c|c|c|c|c|c|c|}
\hline $\begin{array}{l}\text { Attemp } \\
\text { t no }\end{array}$ & 1 & 2 & 3 & 4 & 5 & 6 & 7 & 8 & 9 & 10 \\
\hline $\begin{array}{l}\text { Time } \\
\text { taken }\end{array}$ & $\stackrel{g}{\dot{q}}$ & 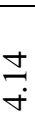 & $\stackrel{n}{\stackrel{n}{+}}$ & $\stackrel{m}{q}$ & $\underset{\text { m. }}{\text { m. }}$ & त़ & $\stackrel{\text { ণิ }}{\forall}$ & n̊ & $\begin{array}{l}n \\
\infty\end{array}$ & $\stackrel{m}{\sim}$ \\
\hline
\end{tabular}

For Right command mean time is: $3.647 \mathrm{sec}$. 


\section{Stop Command:}

\begin{tabular}{|c|c|c|c|c|c|c|c|c|c|c|}
\hline $\begin{array}{l}\text { Atte } \\
\text { mpt } \\
\text { no }\end{array}$ & 1 & 2 & 3 & 4 & 5 & 6 & 7 & 8 & 9 & 10 \\
\hline $\begin{array}{l}\text { Time } \\
\text { take } \\
\text { n }\end{array}$ & $\stackrel{\text { If }}{i}$ & $\stackrel{\tilde{c}}{i}$ & $\stackrel{+}{-}$ & $\stackrel{m}{i}$ & $\underset{\mathrm{i}}{\mathrm{i}}$ & $\begin{array}{l}n \\
\infty \\
i\end{array}$ & $\stackrel{n}{6}$ & $\stackrel{\infty}{\stackrel{\infty}{ }}$ & 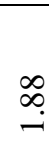 & $\underset{i}{8}$ \\
\hline
\end{tabular}

For Stop command mean time is: $2.072 \mathrm{sec}$.

\section{CONCLUSIONS}

From section 7 some conclusions are drawn which are as listed below. The results are dependent on the time taken by android application to response. If Android mobile is having high processing speed then wheel chair may take less time to operate.

(i) For Forward obstacle, wheel chair stops 20 cm away from the obstacle.

(ii) For Backward obstacle, wheel chair stops $17 \mathrm{~cm}$ away from the obstacle.

(iii) The mean time taken by wheel chair to perform Forward operation is $\mathbf{2 . 2 1 5} \mathbf{~ s e c}$.

(iv) The mean time taken by wheel chair to perform Back operation is $\mathbf{2 . 3 2 6}$ sec.

(v) The mean time taken by wheel chair to perform Left operation is 4.09 sec.

(vi) The mean time taken by wheel chair to perform Right operation is $3.647 \mathrm{sec}$.

(vii) The mean time taken by wheel chair to perform Stop operation is $\mathbf{2 . 0 7 2}$ sec.

(viii) The wheel chair operates for 30 minutes on a small battery of rating $12 \mathrm{~V}, 7.2 \mathrm{AH}$ lead acid battery.

\section{FUTURE SCOPE}

(i) Further advancement in this wheel chair are possible by decreasing the power requirements of the wheel chair or finding a way to automatically charge the battery with the help of motion of the wheel chair or solar panel .

(ii) As using android technology we can also try to use GPS location to get the Location of user.

(iii) A sensor can be used to detect that person is on wheel chair or is he fall down.

\section{ACKNOWLEDGEMENTS}

I am thankful to Dr. S. B. Somani, Principal and Prof. G. S. Gawande, HOD (EXTC) of Shri Sant Gajanan Maharaj College of Engineering, Shegaon for providing lab facilities.

I am highly indebted to Dr. A. M. Agarkar and Prof. R. S. Dhekekar for their valuable Guidance and support during the tenure of the project.

\section{REFERENCES}

[1] "Voice Operated Intelligent Wheelchair" by Ms. S. D. Suryawanshi, Mr. J. S. Chitode , Ms. S. S. Pethakar, “ International Journal of Advanced Research in Computer Science and Software Engineering" Volume 3, Issue 5, May 2013.

[2] "Voice and Touch Screen Based Direction and Speed Control of Wheel Chair for Physically Challenged Using Arduino" by M.Prathyusha, K. S. Roy, Mahaboob Ali Shaik, " International Journal of Engineering Trends and Technology (IJETT)" , Volume4Issue4, April 2013.

[3] "A Wheelchair Steered through Voice Commands and Assisted by a Reactive Fuzzy-Logic Controller" by Gabriel Pires and Urbano Nunes "Journal of Intelligent and Robotic Systems" 34: 301-314, 2002.

[4] "Smart Wheelchairs: A literature Survey", by Richard Simpson "Journal of Rehabilitation Research \& Development", Volume 42, Number 4, Pages 423-436 July/August 2005.

[5] www.techtriks.wordpress.com

[6] http://www.electroschematics.com/wpcontent/uploads/2013/01/PIC16F877A-Datasheet.pdf

[7] http://www.atmel.in/Images/doc2466.pdf

[8] http://www.atmel.in/Images/doc2503.pdf

\section{BIOGRAPHIES}

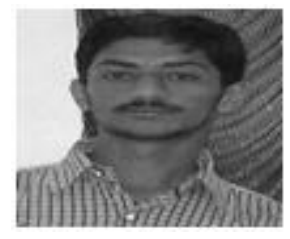

Jayesh K. Kokate Student of ME (Digital Electronics) of Shri Sant Gajanan Maharaj College of Engineering, Shegaon. Done BE and Diploma in Electronics \& Telecommunication.

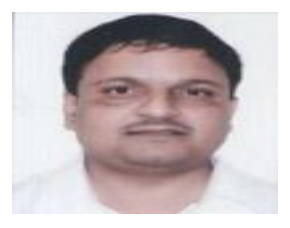

Dr. A. M. Agarkar is associated with Shri Sant Gajanan Maharaj College of Engineering, Shegaon since 1989 and currently working as a Professor of Electronics \& Telecommunication dept. His areas of interest include ANN, Intelligent Systems, Embedded \& VLSI (SOC) systems and Parallel computing. 